\title{
Restricted Axillary Staging in Clinically and Sonographically Node- Negative Early Invasive Breast Cancer (c/iT1-2) in the Context of Breast Conserving Therapy: First Results Following Commencement of the Intergroup-Sentinel-Mamma (INSEMA) Trial
}

\author{
Eingeschränktes Axilla-Staging bei klinisch und sonografisch nodal- \\ negativen Patientinnen mit frühem invasiven Mammakarzinom \\ (c/iT1-2) im Rahmen der brusterhaltenden Therapie: erste Erkennt- \\ nisse nach Start der Intergroup-Sentinel-Mamma-(INSEMA-)Studie
}

Authors

T. Reimer ${ }^{1}$, A. Stachs ${ }^{1}$, V. Nekljudova ${ }^{2}$, S. Loibl ${ }^{2}$, S. Hartmann ${ }^{1}$, K. Wolter ${ }^{3}$, G. Hildebrandt ${ }^{3}$, B. Gerber ${ }^{1}$

\section{Affiliations}

1 Department of Obstetrics and Gynecology, University of Rostock, Rostock, Germany

2 German Breast Group, Neu-Isenburg, Germany

3 Department of Radiotherapy, University of Rostock, Rostock, Germany

Key words

breast cancer, INSEMA trial, nodal status, sentinel lymph node biopsy, radiotherapy

Schlüsselwörter

Mammakarzinom, INSEMA, Nodalstatus, Sentinel-LymphknotenBiopsie, Strahlentherapie

$$
\begin{array}{ll}
\text { received } & 22.9 .2016 \\
\text { revised } & 26.11 .2016 \\
\text { accepted } & 3.12 .2016
\end{array}
$$

\section{Bibliography}

DOI http://dx.doi.org/10.1055/s-0042-122853

Geburtsh Frauenheilk 2017; 77: 149-157 @ Georg Thieme Verlag KG Stuttgart · New York I ISSN 0016-5751

\author{
Correspondence \\ Prof. Toralf Reimer \\ University of Rostock, Department of Obstetrics and Gynecology \\ Südring 81, 18059 Rostock, Germany \\ toralf.reimer@kliniksued-rostock.de
}

Deutsche Version unter:

http://dx.doi.org/10.1055/s-0042-122853

\section{ABSTRACT}

Axillary lymph node status remains an important prognostic factor in early breast cancer. It is regarded as an indicator for (neo)adjuvant systemic treatment and postoperative radiotherapy of the regional lymphatics. Commenced in September 2015, the INSEMA trial is investigating whether operative determination of nodal status as part of breast conserving therapy (BCT) for early stage breast cancer (c/iT1-2 c/iN0) can be avoided without reducing oncological safety. After inclu- sion of 1001 patients there was general acceptance of the complex study design by patients and study doctors so that recruitment for the first randomisation (axillary sentinel lymph node biopsy [SLNB]: yes or no) achieved predicted case numbers. The second randomisation however (SLNB alone versus complete axillary dissection when one or two macrometastases are present at SLNB) recruited fewer cases than expected for the following three reasons: a) the $13 \%$ rate of one or two macrometastases after SLNB in the INSEMA trial collective was lower than expected; b) around $20 \%$ of patients refused the second randomisation; c) there was delayed inclusion of the Austrian study centres, which only recruited for the second randomisation. Lack of knowledge of nodal status when SLNB is avoided represents a new challenge for the postoperative tumour board. In particular decisions on chemotherapy for luminal-like tumours and irradiation of the lymphatics (excluding axilla) must be guided by tumour biological parameters. The INSEMA trial does not provide answers to some important questions, e.g. it remains unclear whether patients without SLNB can be offered partial breast irradiation alone in low-risk situations and whether SLNB can also be avoided in patients with stage T1-2 tumours who have a mastectomy indication.

\section{ZUSAMMENFASSUNG}

Der axilläre Nodalstatus wird beim frühen Mammakarzinom immer noch als wichtiger Prognosefaktor und Indikator für eine (neo-)adjuvante System- und postoperative Strahlentherapie der Lymphabflusswege (LAW) gesehen. Die im September 2015 gestartete INSEMA-Studie untersucht, ob beim frühen Mammakarzinom (c/iT1-2 c/iN0) auf die operative Bestimmung des Nodalstatus im Rahmen der brusterhaltenden Therapie (BET) verzichtet werden kann, ohne dass die onkologische Sicherheit beeinträchtigt wird. Nach Einschluss von $1001 \mathrm{~Pa}-$ tientinnen war die Akzeptanz des komplexen Studiendesigns bei Patientinnen und Prüfärzten gegeben, sodass die Rekrutierung für die erste Randomisierung (axilläre Sentinel-Lymphknoten-Biopsie [SLNB]: ja oder nein) im Rahmen der Fallzahlprognose liegt. Die 2. Randomisierung (SLNB allein versus Komplettierung der Axilladissektion bei 1 oder 2 Makrometastasen in der SLNB) rekrutiert dagegen aus 3 Gründen weniger als erwartet: a) Der Nachweis von 1 bis 2 Makrometastasen nach der SLNB im INSEMA-Kollektiv ist mit 13\% geringer als erwartet; b) etwa $20 \%$ der Patientinnen lehnten die 2 . Randomisierung ab; c) der Einstieg der österreichischen Prüfzentren, die ausschließlich für die 2. Randomisierung rekrutieren, erfolgt zeitlich verzögert. Die Unkenntnis des Nodalstatus bei Verzicht auf die SLNB bringt eine neue Herausforderung für die postoperative Tumorkonferenz. Insbesondere 
die Indikation zur Chemotherapie bei Luminal-like-Tumoren und zur Bestrahlung der LAW (ohne Axilla) muss nun an den tumorbiologischen Parametern ausgerichtet werden. Einige wichtige Fragen können durch die INSEMA-Studie nicht beantwortet werden. Unklar bleibt beispielsweise, ob Patientinnen ohne SLNB eine alleinige Teilbrustbestrahlung in Low-Risk-Situationen angeboten werden kann bzw. ob auch bei Patientinnen mit einer Mastektomieindikation auf die SLNB im Stadium T1-2 verzichtet werden kann.

\section{Introduction}

The Intergroup-Sentinel-Mamma (INSEMA) trial (NCT02466737, GBG75, ABCSG43) is a prospective, randomised trial comparing sentinel lymph node biopsy (SLNB) versus no axillary surgery in patients with early invasive breast carcinoma (clinically/radiologically $\leq 5 \mathrm{~cm}$; c/iT1-2 c/iN0) who are having breast conserving therapy (BCT) including postoperative whole breast irradiation ( $\vee$ Fig. 1). In a second phase, analogous to the ACOSOG Z0011 trial [1], patients with sentinel lymph node positivity are randomised to either no further surgery or complete axillary lymph node dissection (ALND). The INSEMA trial is sponsored by the University Medicine Rostock; it is financed by the Deutsche Krebshilfe $\mathrm{GmbH}$ (German Cancer Aid Ltd); data management is performed by the German Breast Group (GBG) (Neu-Isenburg, Germany). Over 130 German trial centres recruit for both analyses; the "first patient in" was on 17.09.2015 in Rostock. On 09.03.2016 the first patient was recruited in Austria at the Salzburg centre. The remaining Austrian Breast \& Colorectal Cancer Study Group (ABCSG) centres will only recruit for the second randomisation.

The rationale of the study is based on the available data at the time of protocolling (2011-2014) [2,3]. This sees the removal of the axillary sentinel lymph node (SLN) in a critical light - at least in the context of BCT when lymph nodes are normal on palpation and ultrasound. Complete ALND appears to be of no benefit even to patients with one to two positive SLNs whereas avoidance of SLNB could reduce costs (marking, operative capacity, pathology), reduce axilla-related morbidity (e.g. lymphoedema) and improve quality of life [4]. Review of the Rostock Cancer Registry from 2014 and 2015 found that for the Rostock University Women's Hospital $53.1 \%$ of newly diagnosed breast cancer patients fulfilled INSEMA inclusion criteria. Thus results of the INSEMA trial could potentially influence the operative management of every second breast cancer patient.

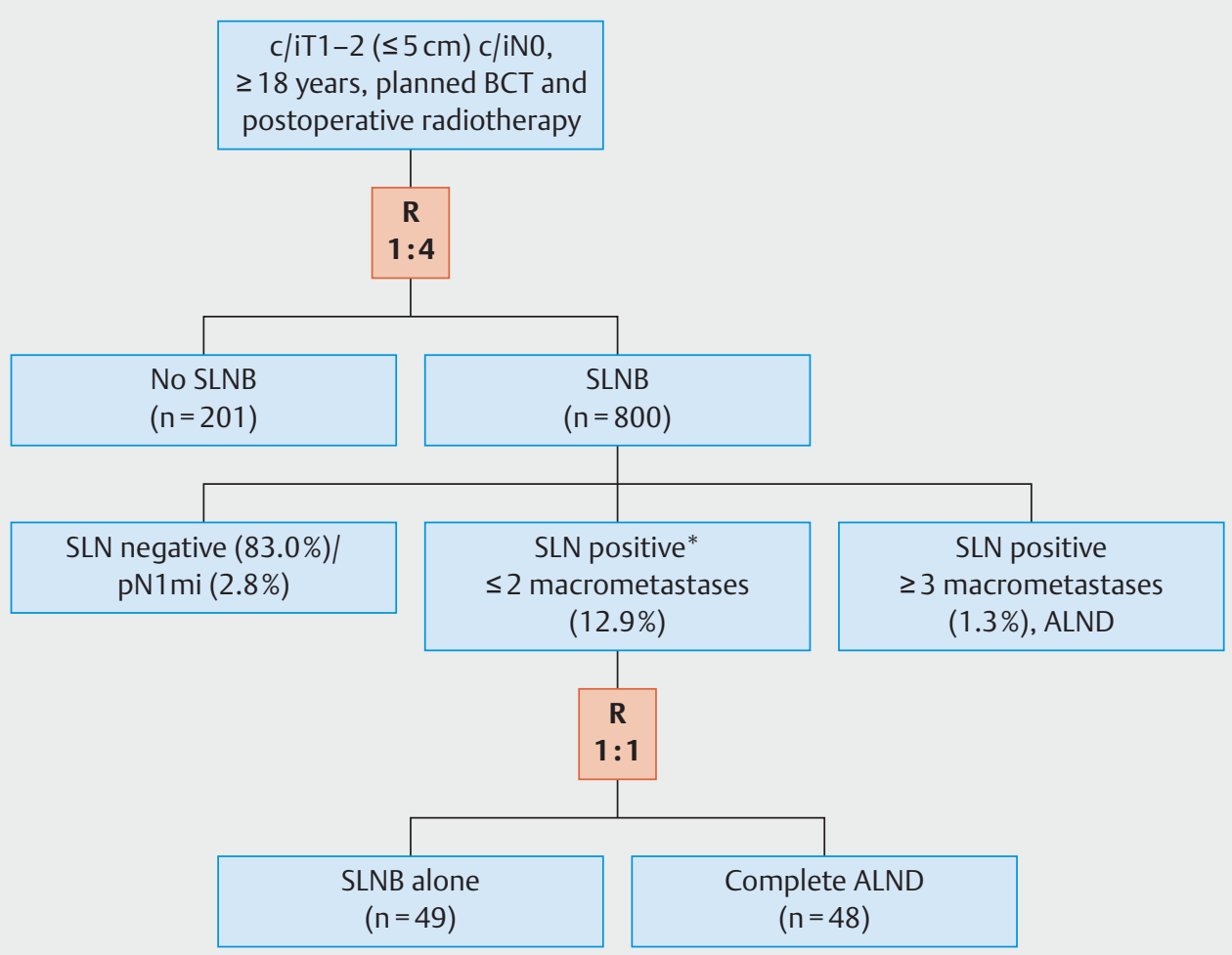

${ }^{*}$ According to protocol amendment \#4 changed to $\leq 3$ macrometastases. Direct inclusion of patients in the rando 2 is then possible for all trial centres.

Fig. 1 Flow chart of the INSEMA trial showing the distribution after recruitment of 1001 patients. 
- Table 1 Selected patient characteristics of the first 1001 INSEMA patients.

\begin{tabular}{|c|c|c|c|c|c|}
\hline Parameter & Category & SLNB $(n=800)$ & No SLNB $(n=201)$ & Total $(n=1001)$ & p-value \\
\hline \multirow[t]{3}{*}{ Age (years) } & mean & 61.1 & 60.0 & 60.9 & 0.236 \\
\hline & median & 61.0 & 60.0 & 61.0 & \\
\hline & $\min -\max$ & $36-87$ & $36-89$ & $36-89$ & \\
\hline \multirow[t]{2}{*}{ BMI $\left(\mathrm{kg} / \mathrm{m}^{2}\right)$} & mean & 27.0 & 27.2 & 27.1 & 0.707 \\
\hline & median & 25.8 & 25.9 & 25.8 & \\
\hline \multirow[t]{2}{*}{ HR status } & ER/PgR negative & $23(2.9 \%)$ & $8(4.0 \%)$ & $31(3.1 \%)$ & 0.493 \\
\hline & ER and/or $\mathrm{PgR}$ positive & 774 (97.1\%) & $193(96.0 \%)$ & 967 (96.9\%) & \\
\hline \multirow[t]{2}{*}{ HER2 status } & negative & $728(92.0 \%)$ & $178(89.4 \%)$ & $906(91.5 \%)$ & 0.255 \\
\hline & positive & $63(8.0 \%)$ & $21(10.6 \%)$ & $84(8.5 \%)$ & \\
\hline \multirow[t]{3}{*}{ Grading } & G1 & $269(33.6 \%)$ & $65(32.3 \%)$ & $334(33.4 \%)$ & 0.942 \\
\hline & G2 & $488(61.0 \%)$ & $125(62.2 \%)$ & $613(61.2 \%)$ & \\
\hline & G3 & $43(5.4 \%)$ & $11(5.5 \%)$ & $54(5.4 \%)$ & \\
\hline \multirow[t]{3}{*}{ Histological subtype } & invasive ductal & $586(73.5 \%)$ & $152(75.6 \%)$ & 738 (73.9\%) & 0.774 \\
\hline & invasive lobular & $89(11.2 \%)$ & $24(11.9 \%)$ & $113(11.3 \%)$ & \\
\hline & mixed or other & $122(15.3 \%)$ & $25(12.5 \%)$ & $147(14.7 \%)$ & \\
\hline \multirow[t]{2}{*}{ Ki-67 } & $\leq 20 \%$ & $648(84.3 \%)$ & 160 (82.9\%) & $808(84.0 \%)$ & 0.661 \\
\hline & $>20 \%$ & $121(15.7 \%)$ & $33(17.1 \%)$ & $154(16.0 \%)$ & \\
\hline
\end{tabular}

\section{Materials and Methods}

\section{Essential inclusion criteria for the INSEMA trial (recent changes according to protocol amendment \#4 from 15.09.2016 in bold type):}

- Histologically confirmed unilateral invasive breast carcinoma (punch biopsy, Mammotome biopsy or open biopsy possible)

- Age $\geq 18$ years

- Tumour size clinically and radiologically $\leq 5 \mathrm{~cm}$ (iT1/iT2) independent of hormone receptor and HER2 status

- Clinically and sonographically tumour-free axillary lymph nodes before biopsy (c/iNO); if cNO/iN+ negative core biopsy or fine needle aspiration of suspicious lymph node required

- No suspicion of distant metastases

- Planned BCT with postoperative whole-breast irradiation and adequate systemic therapy

\section{Essential exclusion criteria for the INSEMA trial:}

- History of carcinoma in the previous 5 years

- Invasive breast cancer treated with neoadjuvant therapy

- c/iT3-T4 tumours

- Planned mastectomy

- Planned exclusive intraoperative partial breast irradiation (e.g. INTRABEAM) or exclusive postoperative partial breast irradiation (e.g. multi-catheter technique); both methods allowed as boost

- Pregnancy and breastfeeding

- Male breast cancer

\section{Study aims}

Statistical analysis in the INSEMA trial is based on non-inferiority so that per protocol analysis is mainly performed. The primary outcome for both study questions is invasive disease-free survival. Secondary outcomes are overall survival, local and axillary recurrence rates and determination of actual applied radiotherapy dose at each axillary level. In addition, analyses of quality of life and translational research in the form of a biobanking program are integrated.

Approximately 6000 patients will be recruited in 130 trial centres in Germany and one in Austria for both INSEMA trial analyses. A further 10 ABCSG centres will contribute 800 cases exclusively for the second randomisation. The 1000th study patient was recruited on 22.06.2016, the INSEMA trial thus linking up with the SOUND study (Sentinel Node versus Observation After Axillary UltraSound, NCT02167490) [4], which has been running since 2012. In the SOUND study 1560 patients with breast tumours up to $2 \mathrm{~cm}$ in size (T1 stage) and BCT are to be randomised $1: 1$ to axillary SLNB versus no axillary surgery. In contrast to the INSEMA trial the primary outcome measure is distant disease-free survival.

\section{Results}

A first analysis of patient characteristics ( $n=1001)$ is summarised in $>$ Table 1. The median age of the study population as a whole was 61 years, though there were somewhat more premenopausal women recruited to the non-SLNB group (<50 years: 17.4 vs. $10.8 \%$ in the SLNB group). Statistical analysis of the age distribution showed no significant difference between the groups $(p=0.051)$. 
- Table 2 Prospective randomised trials with avoidance of axillary lymphadenectomy in patients with early stage breast cancer vs. complete axillary dissection/axillary radiotherapy.

\begin{tabular}{|c|c|c|c|c|c|c|}
\hline Author/Study & Patients & $\mathbf{n}$ & Follow-up & $\begin{array}{l}\text { Axillary } \\
\text { recurrence }\end{array}$ & $\begin{array}{l}\text { Disease-free } \\
\text { survival }\end{array}$ & $\begin{array}{l}\text { Overall } \\
\text { survival }\end{array}$ \\
\hline $\begin{array}{l}\text { Fisher et al. [50] } \\
(2002) \\
\text { NSABP B-04 }\end{array}$ & $\begin{array}{l}\text { All ages, cN0, MRM vs. ME } \\
\text { alone vs. ME plus radia- } \\
\text { tion, no systemic therapy }\end{array}$ & 1079 & $25 y$ & $\begin{array}{l}18.6 \% \text { in ME- } \\
\text { only arm }\end{array}$ & $\begin{array}{l}19 \text { vs. } 19 \text { vs. } \\
13 \% ; p=0.65\end{array}$ & $\begin{array}{l}25 \text { vs. } 26 \text { vs. } \\
19 \% ; p=0.68\end{array}$ \\
\hline $\begin{array}{l}\text { Veronesi et al. [51] } \\
(2005)^{\#}\end{array}$ & $\begin{array}{l}>45 \mathrm{y}, \text { tumour }<1.2 \mathrm{~cm} \\
\mathrm{cN0}\end{array}$ & 435 & $63 \mathrm{mo}$. & 0.5 vs. $1.5 \%$ & $\begin{array}{l}97 \text { vs. } 95 \% \\
p=0.19\end{array}$ & $\begin{array}{l}99 \text { vs. } 97 \% \\
p=0.23\end{array}$ \\
\hline $\begin{array}{l}\text { Rudenstam et al. [52] } \\
\text { (2006) IBCSG 10-93 }\end{array}$ & $>60 \mathrm{y}, \mathrm{pT} 1-2^{*}, \mathrm{cN} 0$ & 473 & $6.6 y$ & $\begin{array}{l}0.9 \text { vs. } 2.5 \% \text {; } \\
\text { n.s. }\end{array}$ & $\begin{array}{l}67 \text { vs. } 66 \% \\
p=0.69\end{array}$ & $\begin{array}{l}75 \text { vs. } 73 \% \\
p=0.77\end{array}$ \\
\hline $\begin{array}{l}\text { Martelli et al. [53] } \\
\text { (2014) }\end{array}$ & $\begin{array}{l}\geq 65 y, \mathrm{p} T 1 \mathrm{cN} 0 \\
\text { tamoxifen }\end{array}$ & 238 & $15 y$ & 0 vs. $6 \%$ & DDFS $p=0.95$ & $p=0.64$ \\
\hline $\begin{array}{l}\text { Agresti et al. [54] } \\
\text { (2014) INT09/98 }\end{array}$ & $\begin{array}{l}\text { 30-65 J., cT1cN0, tamox- } \\
\text { ifen } \pm \text { chemotherapy }\end{array}$ & 565 & $10 y$ & 0 vs. $9 \%$ & $\begin{array}{l}92.4 \text { vs. } 91.3 \% \\
p=0.9\end{array}$ & $\begin{array}{l}93.3 \text { vs. } 91.5 \% \\
p=0.78\end{array}$ \\
\hline \multicolumn{7}{|c|}{$\begin{array}{l}\text { \# Veronesi et al. randomised patients without axillary surgery to no further treatment vs. axillary radiation. } \\
\text { * } 42 \% \text { of patients with tumours }>2 \mathrm{~cm}\end{array}$} \\
\hline $\mathrm{y}=$ years, $\mathrm{mo} .=\mathrm{mont}$ & mastectomy, $\mathrm{MRM}=\mathrm{moc}$ & idical & omy, DDFS & t dicezerefre & & \\
\hline
\end{tabular}

After analysis of preoperative imaging 889 cases (88.9\%) were assigned to stage cT1 $(\leq 2 \mathrm{~cm})$ and 111 cases $(11.1 \%)$ to stage $\mathrm{cT} 2$ $(>2 \mathrm{~cm})$. The vast majority of the 1001 breast carcinomas were hormone receptor positive $(96.9 \%)$. Only $8.5 \%$ of all tumours were HER2 positive and only $5.4 \%$ of all cases were G3 on tumour grading. These figures support the assumption that in Germany triple negative and HER2 positive tumours are currently more likely to be treated during neoadjuvant therapy.

In the SLNB arm ( $n=755$ after exclusion of drop-outs) the detection rate for the sentinel lymph node was 99.5\%. Pathology analysis of 751 SLNBs performed showed the following distribution of nodal status: $83.0 \%$ pN0 $(n=623) ; 2.8 \%$ micrometastasis (pN1mi; $n=21) ; 12.9 \%$ with $1-2$ macrometastases ( $n=97)$; and $1.3 \% \geq 3$ macrometastases $(n=10)$. Thus the case rate of $85.8 \%$ without demonstrable axillary lymph node macrometastasis was significantly above the $70 \%$ predicted at protocolling. This can be credited to the thorough preoperative workup at the trial centres (e.g. ultrasound \pm axillary core biopsy) during INSEMA recruitment. On the other hand many breast centres (internationally too) currently achieve pN0 rates of around $80 \%$ for SLNB through increased screening.

\section{Discussion}

\section{Avoidance of SLNB and oncological safety}

The oncological safety of avoiding SLNB is often questioned during informed consent to INSEMA trial participation. The request for maximal oncological safety from patients and relatives must be weighed up against the desire for adequate cosmesis in the axilla and the avoidance of operative morbidity. Studies from the pre-SLNB era compared ALND to no axillary surgery for clinically tumour-negative axillary lymph nodes. Case numbers were often low, however with adequate long-term follow-up these studies showed that although the rate of axillary recurrence is slightly in- creased, this does not affect disease-free survival or overall survival ( $\triangleright$ Table 2).

When discussing oncological safety it must be mentioned that the randomised trials that lead to the acceptance of SLNB in routine clinical practice had false negative rates of $5-8 \%$, which however did not influence disease-free or overall survival $[5,6]$.

In the IBCSG 23-01 trial 931 patients with SLN micrometastases were randomised to either no further axillary surgery or complete axillary dissection [7]. After adequate systemic therapy, radiotherapy and a median follow-up of 5 years the locoregional recurrence rate $(0.9 \%$ in both arms), disease-free survival ( 87.8 vs. $84.4 \%$ ) and overall survival (98.0 vs. $97.6 \%$ ) were not significantly different. Since publication of these data complete axillary dissection has generally been avoided - even outside of clinical trials - when SLNB shows pN1mi (St. Gallen 2013 consensus recommendation) [8].

\section{Oncological safety with avoidance of complete axillary dissection despite SLNB tumour cell positivity}

The ACOSOG Z0011 trial provides data on this subject that were first presented at the ASCO 2010 and brought up to date after extended follow-up at the ASCO 2016. In the Z0011 trial almost 900 patients with BCT and SLN micro- and macrometastases were randomised to either no further axillary surgery or complete ALND. Here too, after a median follow-up of 9.25 years, there were no significant differences in recurrence rates locally $(5.6 \%$ in the ALND arm vs. $3.8 \%$ in the "SLNB only" arm; $p=0.13$ ) or in the axilla $(0.5 \%$ in the ALND arm vs. $1.5 \%$ in the "SLNB only" arm), nor in locoregional recurrence-free survival $(p=0.36)$ [9]. It is noteworthy that 4 of the total 5 axillary lymph node recurrences in the "SLNB only" arm (1.5\%) occurred within the first five years. Indeed, 3.6\% of cases in the "SLNB only" arm were found to have more than two macrometastases at definitive histology.

The previously mentioned limitations of the Z0011 trial (e.g. $37.5 \%$ only SLN axillary micrometastasis, numerous violations of protocol during postoperative radiotherapy) lead to the com- 
mencement of further validation trials. Almost all subsequent protocols focus on patients with SLN axillary macrometastasis. Interestingly, some study groups extend the inclusion criteria beyond those of the classical Z0011 design: Inclusion of mastectomy patients (POSNOC [10], SENOMAC [11], Dutch BOOG 2013-07 [12], SINODAR ONE [13]); inclusion of patients with SLNB before neoadjuvant systemic treatment, T3 tumours and male patients (SENOMAC [11]); inclusion of patients with more than two macrometastases at SLNB (Dutch BOOG 2013-07, French SERC/IPC 2012-001).

\section{The need for a second INSEMA randomisation}

As a result of the ACOSOG Z0011 trial avoidance of ALND is regarded by many as standard. Thus in the USA $54 \%$ of patients with one or two involved SLNs already no longer undergo complete lymphadenectomy [14]. The Oncology Working Group - Breast (AGO-Mamma) has given this approach (avoidance of complete ALND with one or two involved SLNs and breast conserving operation) a + /- recommendation, thus not yet declaring it standard [15]. The second INSEMA randomisation therefore deals with a still unresolved issue. In order to increase the power of validation studies investigators from the SENOMAC and INSEMA trials will aim for pooled analysis of BCT cases.

The following changes to recruitment for the second study question of the INSEMA trial are contained in the current protocol amendment \#4:

1. Inclusion of patients with one to three macrometastases following SNLB;

2. German trial centres may recruit directly for the second randomisation.

In contrast to the ACOSOG Z0011 - where $37.5 \%$ of patients "only" had axillary micrometastasis - the INSEMA trial will only include patients with macrometastasis, meaning that the axillary tumour load between the two study collectives will differ significantly [16]. It is also expected that postoperative radiotherapy in the two studies will not be identical. In the Z0011 approx. 50\% of patients received a so-called high tangent with significant dose to the axilla levels I and II; in addition $18.9 \%$ of cases had received radiation to the regional lymph drainage areas, which was not consistent with protocol. On the other hand $11 \%$ of patients did not receive postoperative whole-breast irradiation [17]. In the INSEMA protocol ascertainment of the actually administered radiotherapy dose for each axilla level was made a secondary study outcome. Also, a central review of the first three radiation treatment plans in each case was integrated. Up until the end of August 2016144 radiotherapy protocols from 58 centres have been reviewed and are already complete for 24 centres.

\section{Significance of transcapsular spread in involved lymph nodes}

The prognostic significance of lymph node capsule infiltration and capsule rupture with extranodal tumour spread is controversial. For instance capsule infiltration/rupture was classified as pN1biii in the 5th edition of the American Joint Committee on Cancer (AJCC)'s “Cancer Staging Manual”, but in the currently valid 6th edition is not specifically listed $[18,19]$. In the ACOSOG Z0011 tri- al only "matted nodes" or evidence of macroscopic extranodal tumour ("gross extranodal disease") at the time of SNLB were exclusion criteria.

In a current meta-analysis of 5 analysable studies including a total 624 patients (163 with, 461 without transcapsular spread) with a median follow-up of 58 months, patients with transcapsular spread had a significantly increased recurrence rate $(R R=2.07$, $95 \% \mathrm{Cl}: 1.38-3.10, \mathrm{p}<0.0001)$ and mortality $(\mathrm{RR}=2.51 ; 95 \% \mathrm{Cl}$ : 1.66-3.79, $p<0.0001$ ) [20]. Other studies have shown, however, that extracapsular tumour spread $\leq 2 \mathrm{~mm}$, and thus also capsule infiltration alone, did not significantly worsen prognosis [21-24]. Capsule rupture itself has shown significant correlation with further involved axillary lymph nodes and other unfavourable tumour parameters. In a study that took the ACOSOG Z0011 criteria into account (pT1-2, cN0, $\leq 2$ positive SLNs) only 1109 cases from a study population of 11730 were found to have one to two positive SLNs on H\&E staining. Of these, $30 \%(n=331)$ had capsule rupture ( $\leq 2 \mathrm{~mm}: \mathrm{n}=180$; $>2 \mathrm{~mm}: \mathrm{n}=151$ ) [22]. Local operative treatment i.e. complete axillary dissection does not appear to be necessary for transcapsular spread in the current era of modern multimodality treatment. In a study at the Memorial Sloan-Kettering Cancer Center in New York only 45 of 111 patients with capsule rupture underwent axillary dissection. After a median followup of 21 months there was not a single case of local recurrence among the 66 patients without complete axillary dissection [25]. There is currently no standard pathological definition of capsule rupture. Neoplastic emboli, nests of free tumour cells or marginal sinus metastases should not be documented as relevant transcapsular spread [20]. The pathological diagnosis "sentinel macrometastasis with transcapsular spread" does not preclude inclusion in the INSEMA randomisation 2, therefore there is no need for the INSEMA protocol to define these parameters. Other studies (e.g. AMAROS, SENOMAC) also recruit (or have recruited) cases with lymph node metastases and transcapsular spread.

\section{Deciding on irradiation of the regional lymphatics depending on nodal status}

Three prospective randomised trials (MA.20, EORTC, French-trial) [26-28] and one cohort study (DBCG-IMN) [29] have dealt with the effects of irradiating the regional lymphatics (parasternal \pm supraclavicular) in patients with node-positive or node-negative high-risk tumours or tumours with medial location. All three randomised trials found no significant advantage for overall survival (primary study outcome) after a follow-up period of 10 years. A meta-analysis of these three trials did however show a significant effect (HR 0.90; 95\% Cl: 0.82-0.99) [30]. The Danish cohort study DBCG-IMN achieved its primary study outcome (significant difference in overall survival after 8.9 years: $75.9 \%$ with and $72.2 \%$ without parasternal irradiation; $p=0.005)$. This positive effect was however only demonstrated when $\geq 4$ lymph nodes were involved. These data are confirmed by a Swedish cohort study in which irradiation of the regional lymphatics in patients with 1-3 involved lymph nodes was not associated with a survival advantage, only well-known side effects [31]. The AGO treatment guidelines give a single "plus" recommendation (= of limited use, may be used) to irradiation of regional lymphatics in the presence of 1-3 involved axillary lymph nodes only when further risk factors 
- Table 3 Axillary recurrence rates in studies comparing whole breast vs. partial breast irradiation alone in the context of breast conserving treatment.

\begin{tabular}{|c|c|c|c|c|c|c|}
\hline \multirow[t]{2}{*}{ Study } & \multirow[t]{2}{*}{$\begin{array}{l}\text { Number } \\
\text { of cases ( } n \text { ) }\end{array}$} & \multirow[t]{2}{*}{$\begin{array}{l}\text { Proportion } \\
\text { of } \mathrm{pN}+\end{array}$} & \multirow[t]{2}{*}{ Follow-up } & \multicolumn{2}{|c|}{$\begin{array}{l}\text { Regional lymph node } \\
\text { recurrence ( } n \text { ) }\end{array}$} & \multirow[t]{2}{*}{ p-value } \\
\hline & & & & WBI & PBI & \\
\hline Dodwell [55] (2005) & 174 & $41 \%$ (PBI-arm) & 8 years & 4 & 10 & 0.05 \\
\hline Rodriguez [56] (2013) & 102 & $0 \%$ & 5 years & 0 & 0 & n.s. \\
\hline ELIOT [35] (2013) & 1305 & $26 \%$ & 5.8 years & 2 & 9 & 0.03 \\
\hline TARGIT-A [36] (2014) & 3451 & $16 \%$ & 5 years & 6 & 8 & 0.609 \\
\hline GEC-ESTRO [37] (2016) & 1184 & $1 \% \mathrm{pN} 1 \mathrm{mi}$ & 5 years & 1 & 3 & 0.39 \\
\hline
\end{tabular}

are present (medial/central tumour localisation, G2-3, ER/PgR negative, premenopause) [15].

It must however be critically noted that in all the studies on regional lymphatic irradiation mentioned above, tumour biology in terms of intrinsic subtypes was not adequately taken into consideration, and systemic treatments did not match current standards (e.g. no anti-HER2) [32]. In addition, these study populations are not comparable with the INSEMA collective since they have a significantly higher proportion of node-positive cases (MA.20 trial: $90 \% \mathrm{pN}+$, DBCG-IMN: $100 \% \mathrm{pN}+$ ). The current INSEMA protocol (amendment \#4) has adopted irradiation of the regional lymphatics as clearly indicated when 4 or more lymph nodes are involved ( $\geq$ stage pN2a).

\section{Rate of axillary recurrence in studies using partial breast irradiation alone}

It is currently assumed that in the context of BCT axillary recurrence is minimised by postoperative whole breast irradiation, even in patients with negative SLNB [33]. In practice there is significant incidental irradiation of the ipsilateral axilla, at least at level I, even when so-called "standard tangents" are used [34]. This is considered an important contributor to the results of the Z0011 trial. Modern radiotherapy techniques (e.g. RapidArc technology) may soon enable reduction of this "collateral" irradiation of the ipsilateral axilla.

With this in mind the interpretation of published studies with partial breast irradiation alone becomes more interesting. In this context, dependent on tumour localisation, the ipsilateral axilla levels may receive no or only very little irradiation. - Table 3 summarises an analysis of 5 studies on this theme. Among these only the ELIOT study showed a significantly increased regional lymph node recurrence rate [35]. In contrast no significant difference was found between the different treatment arms in the TARGIT-A and GEC-ESTRO trials [36,37]. One explanation for this is certainly the significantly higher proportion of node-positive cases in the ELIOT. Nevertheless the axillary recurrence rate of $1.4 \%$ in the ELIOT study, with intraoperative partial breast irradiation, is still very low. A meta-analysis of three studies, taking 5-8 years of followup into account, found no significant increase in axillary recurrence rate following partial breast irradiation alone [38].

Thus there is no clear evidence that minimising postoperative radiotherapy of the remaining breast in a low-risk SLNB collective increases the axillary recurrence rate. It is still unclear whether the concept of avoiding SLNB can also be applied to patients receiving partial breast irradiation alone. Currently partial breast irradiation alone is not a treatment option for INSEMA trial participants. The results of SOUND and INSEMA will thus not be applicable to this patient group. This interesting and relevant question lends itself to an INSEMA follow-on project.

\section{Deciding on systemic treatment and radiotherapy without knowledge of nodal status}

With subtyping of breast carcinoma according to hormone receptor (HR) status, HER2 status, tumour grade and Ki-67 systemic treatment is planned according to the intrinsic tumour subtypes rather than nodal status [39]. Chemotherapy \pm anti-HER2 therapy is always indicated for triple-negative and HER2 positive tumours (stage pT1b and above). There is consensus in all guidelines and treatment recommendations that chemotherapy is not automatically indicated for luminal-like tumours with axillary lymph node involvement [15, 40-45]. In particular luminal-A subtype tumours with $\leq 3$ involved lymph nodes can be sufficiently treated with endocrine therapy alone [46]. Analysis of the ABCSG-8 study (HR positive cases, endocrine therapy alone) using the PAM50 test to classify tumours according to intrinsic subtypes showed clear differences within the node-positive subgroup $(n=431)$ dependent on luminal status. The 10-year survival rate without distant metastases was $90.6 \%$ for node-positive luminal-A patients and $71.0 \%$ for node-positive luminal-B tumours [47]. Chemotherapy is indicated for the luminal-like subtype when 4 or more lymph nodes are involved ( $\triangleright$ Table 4 ).

Information on the number of involved lymph nodes is naturally missing for cases in the non-SLNB arm of the INSEMA trial. Following the AMAROS data analysis it was expected for INSEMA that approx. $3 \%$ of all luminal-like tumours in a SLNB collective could potentially have more than three lymph nodes involved [48]. In the INSEMA control arm with SLNB after recruitment of the first 1001 patients only 11 of 771 cases (1.4\%) were found to have three or more involved lymph nodes. Of these 11 patients 8 had three, and 1 had 4, 5 and 6 involved nodes respectively so that the proportion of patients with the relevant pN2a tumour stage was only $0.375 \%$. Thus guideline conform systemic treatment is 
- Table 4 Indications for adjuvant postoperative chemotherapy dependent on tumour biology according to the current St. Gallen consensus recommendations [46].

\begin{tabular}{|c|c|c|}
\hline MaCa-subtype & Indications for postoperative chemotherapy & Comments \\
\hline Luminal-like & $\begin{array}{l}\text { - grading G3 } \\
\text { - low-level ER/PgR expression } \\
\text { - high Ki-67 } \\
\text { - extensive lymphovascular invasion } \\
\text { - HER2 positivity (triple-positive) } \\
\text { Not applicable to INSEMA patients in the non-SLNB arm: } \\
\geq 4 \text { positive axillary lymph nodes* }[46]\end{array}$ & $\begin{array}{l}\text { *... Expected rate of pN }+ \text { with } \geq 4 \text { positive lymph } \\
\text { nodes } 3.7 \% \text { of the whole non-SLNB population } \\
\text { (after AMAROS data [ } 57]) \text {. The proportion of lumi- } \\
\text { nal-like cases in INSEMA with pN }+(\geq 4 \text { LKs) will con- } \\
\text { stitute } 3 \% \text { of the non-SLNB population at most. }\end{array}$ \\
\hline HER2 positive & $\begin{array}{l}\text { Chemotherapy in combination with anti-HER2 treatment } \\
\text { from stage pT1b independent of nodal status }\end{array}$ & No anti-HER2 treatment at stage pT1a \\
\hline TNBC (triple-neg.) & Chemotherapy regardless of nodal status & \\
\hline
\end{tabular}

theoretically possible in $99 \%$ of INSEMA patients without SLNB on the basis of tumour biological parameters alone.

The discussion surrounding indications for irradiation of the regional lymphatics (excluding the axilla) dependent on nodal status/number of involved nodes (see above) is similarly controversial. Most guidelines and treatment recommendations regard more than three positive axillary lymph nodes as the only definite indication [49]. This however only applies to a few individual cases within the INSEMA cohort. The current version of the INSEMA protocol (amendment \#4) has taken this treatment recommendation into account following the full text publication of the MA.20 and EORTC data.

\section{Take Home Message}

As anticipated there have been no unexpected results from the INSEMA trial after recruitment of the first 1001 patients. Acceptance of study participation is high among both patients and doctors. Fortunately economic aspects such as DRG downgrading (from DRG J07B to J25Z) through SLNB avoidance have not played an ostensible role for participating study centres. In the longer term however further negotiations with financing institutions/ medical insurance companies will be required in order to unlink the DRG from the SLNB procedure (as is already the case e.g. in Austria). The proportion of patients with pN0/pN1mi-status in the control arm where SLNB was performed is very high $(83 \%$ pN0, $3 \%$ pN1mi). A degree of selection bias at the trial centres before recruitment is probably contributary, high-risk cases being more likely to receive neoadjuvant therapy. The field of neoadjuvant therapy also has approaches that attempt to reduce the radicality of axillary surgery, especially after publication of the SENTINA and ACOSOG Z1071 data. Postoperative treatment decisions with respect to adjuvant systemic and radiotherapy can be made in accordance with guidelines without knowledge of nodal status in almost all cases, based solely on available tumour parameters. Future studies should investigate the avoidance of axillary SLNB in patients with a mastectomy indication and in those with partial breast irradiation alone after breast conserving surgery.

\section{Acknowledgements}

We thank the patients and trial centres for their participation in the INSEMA trial, see $>$ Table $\mathbf{5}$ for the top 10 recruiting trial centres. The INSEMA trial is financially supported by the Deutsche Krebshilfe gGmbH (Bonn, Projekt 110580). Mrs S. Klöcking enabled access to data from the Rostock clinical cancer registry.

- Table 5 Top 10 INSEMA trial recruiting centres (at 30.06.2016; $\mathrm{n}=1000$ for Rando1).

\begin{tabular}{|l|l|l|l|}
\hline Trial centre & Location & Patients (rando1) \\
\hline University Women's Hospital at Klinikum Südstadt & Rostock & 73 \\
\hline University Hospital & Ulm & 37 & 8 \\
\hline Ev. Waldkrankenhaus Spandau & Berlin & 33 & 3 \\
\hline University Hospital & Heidelberg & 30 & 2 \\
\hline Klinikum Hanau GmbH & Hanau & 30 & 30 \\
\hline Breast Centre/Practice Network & Troisdorf & 2 \\
\hline Niels-Stensen-Kliniken, Franziskus-Hospital Harderberg & Georgsmarienhütte & 29 \\
\hline HELIOS Klinikum & Schwerin & 29 \\
\hline Klinikum Worms gGmbH & Worms & 25 \\
\hline Klinikum Esslingen & Esslingen a. N. & 25 \\
\hline
\end{tabular}




\section{Conflict of Interest}

None.

\section{References}

[1] Giuliano AE, McCall L, Beitsch P et al. Locoregional recurrence after sentinel lymph node dissection with or without axillary dissection in patients with sentinel lymph node metastases: the American College of Surgeons Oncology Group Z0011 randomized trial. Ann Surg 2010; 252: $426-432$

[2] Gerber B, Heintze K, Stubert J et al. Axillary lymph node dissection in early-stage invasive breast cancer: is it still standard today? Breast Cancer Res Treat 2011; 128: 613-624

[3] Reimer T, Hartmann S, Stachs A et al. Local treatment of the axilla in early breast cancer: concepts from the national surgical adjuvant breast and bowel project B-04 to the planned intergroup sentinel mamma trial. Breast Care (Basel) 2014; 9: 87-95

[4] Gentilini O, Botteri E, Dadda P et al. Physical function of the upper limb after breast cancer surgery. Results from the SOUND (Sentinel node vs. Observation after axillary Ultra-souND) trial. Eur ] Surg Oncol 2016; 42: 685-689

[5] Lyman GH, Temin S, Edge SB et al. Sentinel lymph node biopsy for patients with early-stage breast cancer: American Society of Clinical Oncology clinical practice guideline update. J Clin Oncol 2014; 32: 1365-1383

[6] Galimberti V, Manika A, Maisonneuve P et al. Long-term follow-up of 5262 breast cancer patients with negative sentinel node and no axillary dissection confirms low rate of axillary disease. Eur J Surg Oncol 2014; 40: $1203-1208$

[7] Galimberti V, Cole BF, Zurrida S et al. Axillary dissection versus no axillary dissection in patients with sentinel-node micrometastases (IBCSG 2301): a phase 3 randomised controlled trial. Lancet Oncol 2013; 14 : 297-305

[8] Goldhirsch A, Winer EP, Coates AS et al. Personalizing the treatment of women with early breast cancer: highlights of the St Gallen International Expert Consensus on the Primary Therapy of Early Breast Cancer 2013. Ann Oncol 2013; 24: 2206-2223

[9] Giuliano AE, Ballman K, McCall L et al. Locoregional recurrence after sentinel lymph node dissection with or without axillary dissection in patients with sentinel lymph node metastases: long-term follow-up from the American College of Surgeons Oncology Group (Alliance) ACOSOG Z0011 randomized trial. Ann Surg 2016; 264: 413-420

[10] Goyal A, Dodwell D. POSNOC: a randomised trial looking at axillary treatment in women with one or two sentinel nodes with macrometastases. Clin Oncol (R Coll Radiol) 2015; 27: 692-695

[11] Senomac. 2016. Online: www.senomac.se; last access: 20.09.2016

[12] van Roozendaal LM, de Wilt JH, van Dalen T et al. The value of completion axillary treatment in sentinel node positive breast cancer patients undergoing a mastectomy: a Dutch randomized controlled multicentre trial (BOOG 2013-07). BMC Cancer 2015; 15: 610

[13] Tinterri C, Canavese G, Bruzzi P et al. SINODAR ONE, an ongoing randomized clinical trial to assess the role of axillary surgery in breast cancer patients with one or two macrometastatic sentinel nodes. Breast 2016; 30: $197-200$

[14] Caretta-Weyer H, Greenberg CG, Wilke LG et al. Impact of the American College of Surgeons Oncology Group (ACOSOG) Z0011 trial on clinical management of the axilla in older breast cancer patients: a SEER-medicare analysis. Ann Surg Oncol 2013; 20: 4145-4152

[15] AGO. Diagnostic and treatment of early and metastatic breast cancer. 2016. Online: http://www.ago-online.org; last access: 20.09.2016
[16] Giuliano AE, Hunt KK, Ballman KV et al. Axillary dissection vs. no axillary dissection in women with invasive breast cancer and sentinel node metastasis: a randomized clinical trial. JAMA 2011; 305: 569-575

[17] Jagsi R, Chadha M, Moni J et al. Radiation field design in the ACOSOC Z0011 (Alliance) Trial. J Clin Oncol 2014; 32: 3600-3606

[18] Greene FL, Page DL, Fleming ID, Fritz AG, Balch CM, Haller DG, Morrow M, eds. AMERICAN JOINT COMMITTEE ON CANCER: Cancer Staging Manual. 6th ed. New York: Springer; 2002

[19] Fleming ID, Henson DE. AJCC Cancer Staging Manual. Philadelphia, PA Lippincott-Raven; 1997

[20] Nottegar A, Veronese N, Senthil M et al. Extra-nodal extension of sentinel lymph node metastasis is a marker of poor prognosis in breast cancer patients: a systematic review and an exploratory meta-analysis. Eur | Surg Oncol 2016; 42: 919-925

[21] Choi AH, Blount S, Perez MN et al. Size of extranodal extension on sentinel lymph node dissection in the American College of Surgeons Oncology Group Z0011 trial era. JAMA Surg 2015; 150: 1141-1148

[22] Gooch J, King TA, Eaton A et al. The extent of extracapsular extension may influence the need for axillary lymph node dissection in patients with T1-T2 breast cancer. Ann Surg Oncol 2014; 21: 2897-2903

[23] Mittendorf EA, Hunt KK, Boughey JC et al. Incorporation of sentine lymph node metastasis size into a nomogram predicting nonsentinel lymph node involvement in breast cancer patients with a positive sentinel lymph node. Ann Surg 2012; 255: 109-115

[24] Caudle AS, Kuerer HM, Le-Petross HT et al. Predicting the extent of nodal disease in early-stage breast cancer. Ann Surg Oncol 2014; 21: 34403447

[25] Dengel LC, King TA. The presence and extent of extracapsular extension (ECE) and the need for axillary lymph node dissection (ALND) in patients who meet ACOSOG Z11 eligibility criteria. J Clin Oncol 2013; 31 (Suppl.): Abstr. 1019

[26] Whelan TJ, Olivotto IA, Parulekar WR et al. Regional nodal irradiation in early-stage breast cancer. N Engl J Med 2015; 373: 307-316

[27] Poortmans PM, Collette S, Kirkove $C$ et al. Internal mammary and media supraclavicular irradiation in breast cancer. N Engl J Med 2015; 373: 317-327

[28] Hennequin C, Bossard N, Servagi-Vernat S et al. Ten-year survival results of a randomized trial of irradiation of internal mammary nodes after mastectomy. Int J Radiat Oncol Biol Phys 2013; 86: 860-866

[29] Thorsen LB, Offersen BV, Dano H et al. DBCG-IMN: a population-based cohort study on the effect of internal mammary node irradiation in early node-positive breast cancer. J Clin Oncol 2016; 34: 314-320

[30] Budach W, Bölke E, Kammers K et al. Adjuvant radiation therapy of regional lymph nodes in breast cancer - a meta-analysis of randomized trials- an update. Radiat Oncol 2015; 10: 258

[31] Nordenskjold AE, Fohlin H, Albertsson P et al. No clear effect of postoperative radiotherapy on survival of breast cancer patients with one to three positive nodes: a population-based study. Ann Oncol 2015; 26 : 1149-1154

[32] Speers C, Pierce LJ. Postoperative radiotherapy after breast-conserving surgery for early-stage breast cancer: a review. JAMA Oncology 2016; 2: 1075-1082

[33] van Wely B], Teerenstra S, Schinagl DA et al. Systematic review of the effect of external beam radiation therapy to the breast on axillary recurrence after negative sentinel lymph node biopsy. Br J Surg 2011; 98 : 326-333

[34] Belkacemi Y, Allab-Pan Q, Bigorie V et al. The standard tangential fields used for breast irradiation do not allow optimal coverage and dose distribution in axillary levels I-II and the sentinel node area. Ann Oncol 2013; 24: $2023-2028$ 
[35] Veronesi U, Orecchia R, Maisonneuve P et al. Intraoperative radiotherapy versus external radiotherapy for early breast cancer (ELIOT): a randomised controlled equivalence trial. Lancet Oncol 2013; 14: 1269-1277

[36] Vaidya JS, Wenz F, Bulsara M et al. Risk-adapted targeted intraoperative radiotherapy versus whole-breast radiotherapy for breast cancer: 5-year results for local control and overall survival from the TARGIT-A randomised trial. Lancet 2014; 383: 603-613

[37] Strnad V, Ott OJ, Hildebrandt G et al. 5-year results of accelerated partial breast irradiation using sole interstitial multicatheter brachytherapy versus whole-breast irradiation with boost after breast-conserving surgery for low-risk invasive and in-situ carcinoma of the female breast: a randomised, phase 3, non-inferiority trial. Lancet 2016; 387: 229-238

[38] Marta GN, Macedo CR, Carvalho Hde A et al. Accelerated partial irradiation for breast cancer: systematic review and meta-analysis of 8653 women in eight randomized trials. Radiother Oncol 2015; 114: 42-49

[39] Sorlie T, Perou CM, Tibshirani R et al. Gene expression patterns of breast carcinomas distinguish tumor subclasses with clinical implications. Proc Natl Acad Sci U S A 2001; 98: 10869-10874

[40] Anampa J, Makower D, Sparano JA. Progress in adjuvant chemotherapy for breast cancer: an overview. BMC Med 2015; 13: 195

[41] Freedman OC, Fletcher GG, Gandhi S et al. Adjuvant endocrine therapy for early breast cancer: a systematic review of the evidence for the 2014 Cancer Care Ontario systemic therapy guideline. Curr Oncol 2015; 22: S95-S113

[42] Gandhi S, Fletcher GG, Eisen A et al. Adjuvant chemotherapy for early female breast cancer: a systematic review of the evidence for the 2014 Cancer Care Ontario systemic therapy guideline. Curr Oncol 2015; 22: S82-S94

[43] Gradishar W], Anderson BO, Balassanian R et al. NCCN Guidelines Insights Breast Cancer, Version 1.2016. J Natl Compr Canc Netw 2015; 13: 1475-1485

[44] Henry NL, Somerfield MR, Abramson VG et al. Role of patient and disease factors in adjuvant systemic therapy decision making for earlystage, operable breast cancer: American Society of Clinical Oncology Endorsement of Cancer Care Ontario Guideline Recommendations. J Clin Oncol 2016; 34: 2303-2311

[45] Mates M, Fletcher GG, Freedman OC et al. Systemic targeted therapy for HER2-positive early female breast cancer: a systematic review of the evidence for the 2014 Cancer Care Ontario systemic therapy guideline. Curr Oncol 2015; 22: S114-S122
[46] Coates AS, Winer EP, Goldhirsch A et al. Tailoring therapies-improving the management of early breast cancer: St Gallen International Expert Consensus on the Primary Therapy of Early Breast Cancer 2015. Ann Oncol 2015; 26: 1533-1546

[47] Gnant M, Filipts M, Greil R et al. Predicting distant recurrences in receptor-positive breast cancer patients with limited clinicopathological risk: using the PAM50 risk of recurrence score in 1478 postmenopausal patients of the ABCSG- 8 trial treated with adjuvant endocrine therapy alone. Ann Oncol 2014; 25: 339-345

[48] Straver ME, Meijnen P, van Tienhoven G et al. Role of axillary clearance after a tumor-positive sentinel node in the administration of adjuvant therapy in early breast cancer. J Clin Oncol 2010; 28: 731-737

[49] Burstein HJ, Morrow M. Nodal irradiation after breast-cancer surgery in the era of effective adjuvant therapy. N Engl J Med 2015; 373: 379-381

[50] Fisher B, Anderson S, Bryant J et al. Twenty-year follow-up of a randomized trial comparing total mastectomy, lumpectomy, and lumpectomy plus irradiation for the treatment of invasive breast cancer. N Engl J Med 2002; 347: 1233-1241

[51] Intra M, Trifiro G, Viale G et al. Second biopsy of axillary sentinel lymph node for reappearing breast cancer after previous sentinel lymph node biopsy. Ann Surg Oncol 2005; 12: 895-899

[52] Rudenstam CM, Zahrieh D, Forbes JF et al. Randomized trial comparing axillary clearance versus no axillary clearance in older patients with breast cancer: first results of International Breast Cancer Study Group Trial 10-93. J Clin Oncol 2006; 24: 337-344

[53] Martelli G, Boracchi P, Orenti A et al. Axillary dissection versus no axillary dissection in older T1N0 breast cancer patients: 15-year results of trial and out-trial patients. Eur J Surg Oncol 2014; 40: 805-812

[54] Agresti R, Martelli G, Sandri M et al. Axillary lymph node dissection versus no dissection in patients with T1N0 breast cancer: a randomized clinical trial (INT09/98). Cancer 2014; 120: 885-893

[55] Dodwell DJ, Dyker K, Brown J et al. A randomised study of whole-breast vs. tumour-bed irradiation after local excision and axillary dissection for early breast cancer. Clin Oncol (R Coll Radiol) 2005; 17: 618-622

[56] Rodriguez N, Sanz X, Dengra J et al. Five-year outcomes, cosmesis, and toxicity with 3-dimensional conformal external beam radiation therapy to deliver accelerated partial breast irradiation. Int J Radiat Oncol Biol Phys 2013; 87: 1051-1057

[57] Straver ME, Meijnen P, van Tienhoven G et al. Sentinel node identification rate and nodal involvement in the EORTC 10981-22023 AMAROS trial. Ann Surg Oncol 2010; 17: 1854-1861 